\title{
Gender transit as a factor of anxiety of personality of female students
}

\author{
Zinaida Rjabikina, Tatyana Hozjainova*, Polina Hozjainova, and Pavel Prisjagin
}

Kuban State University, department personality psychology and general psychology, 350040, Krasnodar, street Stavropolskaya, 149, Russia

\begin{abstract}
Problems regarding the transformation of gender identification of female students are analyzed in the article. Under consideration are the results of researches, testifying the reduction of femininity of females and increasing of masculinity. The conclusion on relation of gender characteristics (femininity masculinity) with such integral indicator of state of personality as anxiety has been statistically confirmed. It has been determined, that domination of masculine characteristics of female students is accompanied with increased level of anxiety, while feminine characteristics are related to moderate anxiety. It has been concluded, that when masculinization is increased, the anxiety of females is explained by their orientation to increased level of ambitions, responsibility, social activity, which conditions more

complicated existence of females.
\end{abstract}

The present epoch is given different labels, focused on variability: «liquid modernity» ( $\mathrm{Z}$. Bauman), «runaway works» (A. Giddens), society of global transformations [1] etc. Evidently it is a transit situation of a civilizational shift, causing problems at all levels of relation of a person towards the world (S. Hantington, I. Wallerstein, F. Fukuyama). Therefore, there are contradictions and different crisis phenomenon of personality.

The crucial aspect of «liquid modernity» is gender transformations of personality, strengthening uncertainty, which people suffer [2].

By historical standards, the necessity in reflection, interpretation of psychological and social transformations of women's and men's personality appeared in the society not a long time ago as a result of women's fight for their rights (B.G. Anan'ev, K. Gilligan, P. Burd'e, S. Bem etc.). Perceptions about a direct determination of psychological particularities of personality by its biological sex have been dispelled, relations of gender status, determining both psychological type of personality and particularities of its existence, have been registered and empirically confirmed.

First of all, gender status change influenced women. They learn «male» professions, make carrier, develop within the society, not limiting themselves only to family obligations and increasingly applying masculine behaviour strategies [3].

The status of men and women continues to change in modern society

\footnotetext{
* Corresponding author: h.p.m@mail.ru
} 
(E.A. Zdravomyslova, I.S. Kletsina, I.N. Tartakovskaja, L.N. Ozhigova etc.). Gender criteria are also changing, new identification indicators of gender status of personality are appearing and becoming stronger. Such changes refer also to the educational process [4]. Psychological researches present mostly all the problems of sex differentiation within studying personal particularities of pupils. Problems of gender particularities of students are slightly less studied.

In our research on the sample of female students (115 people at age of 18-20 years), data on modern criteria of femininity-masculinity-androgyny typical to this social category has been received. List of personal characteristics, which was included to the questionnaire by Sandra Bem and which was a criteria to differentiate respondents on base of gender status, has been proposed for evaluation. Upon the results of the research, due to changes in perceptions of female-male, $50 \%$ out of the list of masculine and feminine characteristics were relocated to the list of androgynous parameters. It demonstrates the actual changes of the structure of personal parameters, applied to make the description from the sexual identity point of view. Lists of feminine and masculine characteristics are «becoming poorer» and the majority of such characteristics is considered by our contemporaries as androgynous, i.e. not related to the sex of people.

In self-description of female students androgynous characteristics dominate up to $78 \%$ and only $22 \%$ are referred to feminine features. In the description of «ideal» of personality, which can be conditionally considered as a way of self-development, female students included: $60 \%$ of androgynous features, $27 \%$ of masculine features and only $13 \%$ of feminine features. That means that already not very feminine young women are focused on decreasing their being feminine and increasing masculinity.

Although the understanding of what is happening to the personality is conditioned by general trends of social process (transitivity and general increase of dynamism), it is complicated by the fact, that realization of such trends differs in various spaces of existence. Involvement of a person in transformations is different, which «forces» the person to redefine, transform his self-identification.

For example, P.M. Hozjainova in her researches shows, that woman's masculinization in conditions of incomplete family and maternal functions is more a negative trend. The research shows, that in complicated conditions of objective existence of mothers, who raise a child in an incomplete family, the masculinity is often forced. And when the masculinity of women increases, co-existence with a child is characterized by destructive elements. Mothers become more supervisory, inconsistence in raising up a child becomes stronger, emotional distance with a child may increase [5].

In our next research we considered the issue of impact of female students' masculinization on the states of educational existence, which the female students go through. As integrative criteria, indicators of state and trait anxiety have been chosen.

Anxiety was studied by means of Ch. D. Spilberger's method, state and trait anxiety in Hanin's adaptation, which includes indicators of state and trait anxiety. In order to study the gender characteristics of the students, masculinity-femininity XII scale of Freiburg Personality Inventory FPI form B was used in adaptation of A.A. Krylov, E.I. Roginskaja. Also the results of method «Man in the rain» have been analysed within the research, the interpretation of such method gives the opportunity to evaluate the presence of both the indicators of anxiety and gender characteristics of masculinity and femininity in the picture drawn by a respondent. To substantiate statistically correctness of received results the Pearson's correlation coefficient has been applied. 60 female students participated in the research, at the age from 21 to 24 years.

Analysis of empirical data upon the Spilberger's method regarding the anxiety of respondents showed, that average results within a group slightly exceed 44 points, which means the moderate anxiety and constitute 45,7 points of trait anxiety and 47,9 points of 
state anxiety indicator. Increased state anxiety is registered to $50 \%$ of respondents and $52 \%$ respondents have increased trait anxiety.

Upon the results of the study according to FPI method, 52\% of residents had domination of masculine features, to which courage, resoluteness, domination etc. are referred. And $48 \%$ of females are inclined to feminine features, to which traditionally femininity, tenderness, attention etc. are referred.

The results of the method «Man in the rain» confirmed trends in distribution of respondents by anxiety level as well as by expressed gender characteristics.

Thus, by presence or absence on pictures of anxiety indicators, the girls were divided almost equally. Girls with increased anxiety had more on their pictures irregular or double lines, hatchings, chaotic hatch of the rain, protection elements, such as umbrella, shelter, clothes etc., were missing and there were puddles and dirt on the picture. For what regards the feminine and masculine characteristics the girls were divided in two groups: $55 \%$ masculine and $45 \%$ feminine characteristics.

Then anxiety indicators upon the Spilberger's method and gender characteristics of girls upon the FPI method have been correlated (table 1).

Table 1. Distribution of girls with domination of feminine and masculine characteristics as per the state anxiety levels

\begin{tabular}{|c|c|c|}
\hline Gender characteristics & Low and moderate anxiety & High anxiety \\
\hline Masculinity & $32 \%$ & $68 \%$ \\
\hline Femininity & $67 \%$ & $33 \%$ \\
\hline
\end{tabular}

It results from table 1, that distribution of girls with domination of masculinity is asymmetrical as per the anxiety level. Most of them is referred to the group with high state anxiety. In the group of girls with domination of femininity there is an opposite relation: most of them has low and moderate anxiety. It can be concluded, that masculine characteristics are more often related to the increased state anxiety and feminine characteristics are related more to the low and moderate anxiety.

The same data were received for the level of state anxiety in groups where feminine or masculine characteristics dominated (table 2).

Table 2. Distribution of girls with domination of feminine and masculine characteristics for levels of state anxiety

\begin{tabular}{|c|c|c|}
\hline Gender characteristics & Low and moderate anxiety & High anxiety \\
\hline Masculinity & $29 \%$ & $71 \%$ \\
\hline Femininity & $72 \%$ & $27 \%$ \\
\hline
\end{tabular}

In the group of female students with masculine characteristics the majority has high state anxiety, while the majority of female students with feminine characteristics has low and moderate anxiety.

The comparison of indicators of anxiety according to the projective method and FPI method confirmed trends of correlation of anxiety with gender characteristics.

Females with domination of masculine characteristics mostly have high anxiety $59 \%$, accordingly, $41 \%$ have low and moderate anxiety. $67 \%$ of females with domination of femininity have more often low and moderate anxiety, and for $33 \%$ of them high anxiety is 
typical.

Thus, the analysis of received empirical data showed, that there is a correlation between the gender characteristics (masculinity and femininity) and the level of anxiety of female students' personality. Masculine characteristics are related to the increased level of girls' anxiety, while feminine characteristics are related to moderate or low anxiety.

To substantiate statistically correctness of such conclusion correlative analysis between the indicators of anxiety and gender characteristics of respondents has been performed. Correlation has been performed by means of Pearson correlation coefficient between the indicators of FPI method and Spilberger's method. Reliable correlation relations between the indicators of gender characteristics and indicators of trait anxiety $(r=0,44, p=0,001)$ and state anxiety $(r=0,27, p=0,05)$ have been found out. Direct correlation relations mean, that with increase of masculine characteristics of girls the level of their anxiety will become stronger, and with decrease of masculinity and increase of femininity the anxiety will decrease. This trend has been confirmed also while performing the correlation analysis between the indicators femininity-masculinity and the indicators of projective test. Reliable correlation coefficient has been received $-\mathrm{r}=0,39, \mathrm{p}=0,001$.

We find the explanation of such relations in the following: during the process of sexrole identification of personality more often gender particularities of behaviour are formed, which correspond to the natural sex of a person. The fact that the female students use masculinity which is not appropriate to them, with an increased level of ambitions, responsibility, conditions more complicated existence for them. When masculinization is increased, the girls risk non to get over all difficulties, which can lead to an increased anxiety.

That is why, the results of the research show, that masculinization of modern young women becomes a reason to discuss the «benefits» and problems of masculinization. How much natural it is for a person to be equipped with gender characteristics (if follow past cultural traditions) which are not appropriate to his sex.

\section{References}

1. A. Asmolov, Mobilis in mobili: personality in transformations epoch. (Moscow: YASK Publishing House, 2018)

2. L. Ozhigova, Book of Abstracts: XVI European Congress of Psychology, Crisis of a person's gender-based identity. Personal identity in the conditions of existence virtualization. (Moscow University Press, ECP 2019)

3. Russian Academy of sciences, Gender stereotypes in the world being transformed: complex social research experience. (Nauka, 2009)

4. L.V. Shtyleva, Factor of sex in education: gender approach and analysis. (Per Se, 2008)

5. P.M. Khozyainova, Relation of personal particularities and intercommunication of mother with a child in an incomplete family, 1 (Kubsu, 2018) 